\title{
New innovative instruments facilitate both direct-vision and endoscopic-assisted mini-mitral valve surgery
}

\author{
Ryohei Yozu, MD, PhD, ${ }^{a}$ Kazuma Okamoto, MD, PhD, ${ }^{a}$ Mikihiko Kudo, MD, PhD, ${ }^{\mathrm{a}}$ \\ Hidenori Nonaka, BE, ${ }^{\mathrm{b}}$ and David H. Adams, $\mathrm{MD}^{\mathrm{c}}$
}

\begin{abstract}
Objective: The efficacy of new, innovative, original instruments, including a left atrial retractor, silicon annuloplasty ring sizer, modified Cosgrove aortic clamp, and reusable clip for fixing knots of polytetrafluoroethylene (Gore-Tex; WL Gore \& Associates, Inc, Flagstaff, Ariz) suture, to allow surgical exposure in an ideal operative setting of mini-mitral valve repair surgery was verified.
\end{abstract}

\begin{abstract}
Methods: Since 1998, a great deal of innovation has contributed to establishing mitral valve repair via right minithoracotomy as a routine surgical approach for mitral valve insufficiency in 252 cases. During the last 2 years, a newly launched left atrial retractor system attachable to the minithoracotomy spreader has been used. An additional retractor for the posterior wall of the left atrium was attached to the minithoracotomy spreader. The retractor moves flexibly and can be fixed in any favorable position to realize optimal exposure of the mitral valve. A 5 blade size was available depending on the left atrial size and target legion. By using the smallest size, even papillary muscles were exposed easily and clearly. Furthermore, a flexible silicon ring sizer, which could easily pass thorough a narrow working port without tissue damage, was used for sizing the annuloplasty ring. For the surgical technique, multiple chordal reconstructions by the loop technique with polytetrafluoroethylene (GoreTex CV-5 sutures) were applied. A reusable clip for fixing knots made it easy to tie the Gore-Tex suture in the correct position without slipping.
\end{abstract}

\begin{abstract}
Results: No operative mortality occurred. There were 2 conversions to sternotomy for correction of aortic dissection (1) and for coronary artery bypass grafting (1). There were 2 early reoperations for failure of mitral valve repair. The mean aortic crossclamp time was $163.5 \pm 41.6$ minutes. Annuloplasty with a ring or band was performed in all cases except one. The loop technique was used in 173 cases. Among them, a combination of the loop technique and resection and suture technique was used in 56 cases.
\end{abstract}

Conclusions: Newly innovated mini-mitral valve surgical instruments and techniques facilitate both directvision and endoscopic-assisted approaches and accomplish a favorable surgical outcome even in the complex pathology of mitral valve insufficiency. (J Thorac Cardiovasc Surg 2012;143:S82-5)

Endoscopic-assisted mitral valve surgery via minithoracotomy (mini-mitral surgery) has recently evolved and rapidly spread because it is less invasiveness and has a cosmetic advantage. Although mini-mitral surgery is well known as safe and feasible, and is associated with a high repair rate, a low perioperative morbidity, and an excellent durability of repair, ${ }^{1-3}$ this technique is still limited to specific surgeons ${ }^{4}$ because special setting, instruments, and surgical training are essential for this technique. However, mini-mitral surgery realizes great surgical exposure of pathologic lesions in

From the Department of Cardiovascular Surgery, ${ }^{a}$ Keio University, Tokyo, Japan; UNIMEDIC, ${ }^{\mathrm{b}}$ Tokyo, Japan; and Department of Cardiothoracic Surgery, ${ }^{\mathrm{c}}$ Mount Sinai Medical Center, New York, NY.

Disclosures: Ryohei Yozu, Kazuma Okamoto, Mikihiko Kudo, Hidenori Nonaka, and David H. Adams have nothing to disclose with regard to commercial support.

Presented at The American Association for Thoracic Surgery Mitral Conclave, New York, New York, May 5-6, 2011.

Received for publication May 15, 2011; accepted for publication May 26, 2011; available ahead of print July 1, 2011.

Address for reprints: Kazuma Okamoto, MD, PhD, Department of Cardiovascular Surgery, Keio University, Shinanomachi 35, Shinjuku, Tokyo, 160-8582 Japan (E-mail: kazuma_okamoto@mac.com).

0022-5223/\$36.00

Copyright (C) 2012 by The American Association for Thoracic Surgery doi: $10.1016 /$ j.jtcvs.2011.05.026 the mitral valve, and complex surgical procedures can be performed as in the median-sternotomy approach if the surgeon knows how to prepare for the ideal operative setting with optimal instruments. In regard to the technical aspect, special training with endoscopic surgical instruments and surgical strategy, which is different from the sternotomy case and arranged for mini-mitral surgery, is necessary to achieve favorable surgical results. The efficacy of new, innovative, original instruments and an operative setting in minimitral surgery were verified, including a left atrial retractor, silicon annuloplasty ring sizer, modified Cosgrove aortic clamp, and reusable knot clip to facilitate fixing knots of polytetrafluoroethylene (PTFE) (Gore-Tex; WL Gore \& Associates, Inc, Flagstaff, Ariz) suture in an ideal position.

\section{MATERIALS AND METHODS}

From 1998 to April 2011, 252 patients underwent mitral valve repair via a right minithoracotomy for treatment of mitral valve regurgitation. Several innovations have contributed to establishing mitral valve repair via right minithoracotomy as a routine surgical approach. The mean age of patients was $51.1 \pm 13.9$ years, and $36.9 \%$ were female. During the last 2 years, a newly launched left atrial retractor system attachable to the minithoracotomy spreader was developed and has been used. 


\section{Abbreviation and Acronym}

PTFE $=$ polytetrafluoroethylene
In routine mini-mitral surgery, a right anterolateral minithoracotomy of 6 to $8 \mathrm{~cm}$ was made thorough the fourth intercostal space. In cases with difficult exposure, the fourth costal bone was cut to make a larger working space. This bone was repaired with a hydroxyapatite-poly-L-lactide plate (Osteotrans MX; Takiron Co Ltd, Osaka, Japan) at the end of the surgery, and pseudoarthrosis at the rib-costal cartilage was prevented. ${ }^{5}$ Cardiopulmonary bypass was established with the femoral artery (16F-20F FEMFlex II arterial cannula; Edwards Lifesciences, Irvine, Calif), femoral vein (20F-24F VFEM venous cannula, Edwards Lifesciences), and right jugular vein (16F FEM-Flex II arterial cannula, Edwards Lifesciences) cannulation under transesophageal echocardiography guidance. The heart was arrested with antegrade cold blood cardioplegia infusion through a root cannula under direct crossclamping of the ascending aorta with a modified Cosgrove flexible clamp. Infusion of the cardioplegia was repeated every 30 minutes with topical cooling. The mitral valve was exposed thorough the interatrial grove approach with a left atrial retractor attached to a minithoracotomy spreader and an additional retractor for the posterior wall of the left atrium attached to the spreader. Multiple chordal reconstructions by the loop technique ${ }^{6,7}$ with PTFE Gore-Tex CV-5 sutures were applied for correction of prolapsed leaflet rather than the resection and suture technique since $2005{ }^{8}$ We routinely prepare the PTFE loops in the same length in almost all cases and adjust the efficient length of the neochordae with the secondary loop for the mitral leaflet depending on the size of the left ventricle and the part of the prolapsed leaflet (loop-in-loop technique). A reusable clip as a substitution for the neurosurgery clip was used to tie the PTFE suture firmly in the correct position without slipping. A flexible silicon ring sizer was used to choose the annuloplasty ring size so it can pass easily thorough a narrow working port without tissue damage. All manipulations in the heart were performed under endoscope assistance. However, surgeons did not always use endoscopic vision and used direct vision when they were comfortable with it.

\section{RESULTS}

No operative mortality after the surgery occurred (Table 1). There were 2 intraoperative conversions to median sternotomy for correction of retrograde aortic dissection (1) and for coronary artery bypass grafting to the left anterior descending artery area (1). There were 2 early reoperations for mitral valve repair failure and 3 reoperations for bleeding. No severe cerebral complication occurred. Since the new retractor was launched in 2010, there has been no conversion to median sternotomy and reoperation for bleeding among 53 cases. The mean aortic crossclamp time was $163.8 \pm$ 42.0 minutes. Annuloplasty with ring or band was done in all but 1 case. The loop technique was used in 173 cases $(68.6 \%)$. Among them, a combination of the looptechnique and resection-and-suture technique was used in 56 cases with complicated mitral valve pathology. After 2010 , the loop technique was used in 47 cases $(88.7 \%)$.

\section{DISCUSSION}

The newly developed left atrial retractor system, including a minithoracotomy spreader, a left atrial blade, and an
TABLE 1. Surgical outcome between 1998 and April $2011(n=252)$

\begin{tabular}{lc}
\hline Age, y & $51.1 \pm 13.9$ \\
Male/female & $159 / 93$ \\
Operative mortality & 0 \\
Conversion to sternotomy & 2 \\
Early reintervention & \\
$\quad$ Failure of mitral valve repair & 2 \\
$\quad$ Surgical bleeding & 3 \\
Aortic crossclamp time & $163 \pm 42.0$ \\
Loop technique & $173(68.6 \%)$ \\
$\quad$ After 2010 & $47 / 53(88.7 \%)$ \\
Loop technique + resection and suture & $56(22.2 \%)$ \\
\hline
\end{tabular}

additional retractor for the posterior wall of the left atrium, is specialized for mini-mitral surgery and can solve all kinds of difficulties in exposure of the mitral valve. The advantage of this mini-valve system is the flexibility. It moves flexibly to various positions and has good positioning of retractors for optimum exposure depending on the situation and the surgeon's choice. A 5 blade size is available depending on the left atrial size and target legion. To adapt the size of the blade to the pathologic legion, the left atrial retractor can be exchanged easily to the other size under fixed optimal exposure. By retraction of the anterior mitral leaflet toward the anterior wall of the left ventricle with the smallest size blade deeply inserted, even papillary muscles can be exposed easily and clearly on the straight view through the small working port. This function enables comfortable manipulation to the papillary muscle in chordal reconstruction with the loop technique. The exposure of the P2 to P3 area of the mitral valve usually is difficult because of elevation of the left atrial wall. To solve this problem, an additional retractor attachable to the minithoracotomy retractor can push the left atrial wall away from the surgeon's sight. In case of unfavorable exposure of the P1 area, the additional retractor can be used alternatively for retraction of the anterolateral side of the left atrial wall.

Correct sizing of the annuloplasty ring is an important and critical part of the mitral valve repair but is difficult through a small working port. A homemade flexible silicon ring sizer was developed as the same size as the official sizer of the Physio II mitral annuloplasty ring (Edwards Life Science). This can easily pass thorough a narrow working port without tissue damage and is helpful for correct sizing under endoscopic vision.

To repair a prolapsed leaflet in the mitral valve, the gold standard has been the resection-and-suture technique of the prolapsed leaflet, which has demonstrated excellent longterm results. ${ }^{9}$ In contrast, the "respect rather than resect" approach proposed by Perier and colleagues, ${ }^{10}$ which respects leaflet tissue as an important component of the coaptation surface and preserves leaflet without resection, is widely accepted because it allows a larger coaptation area than the resection-and-suture technique and has an 

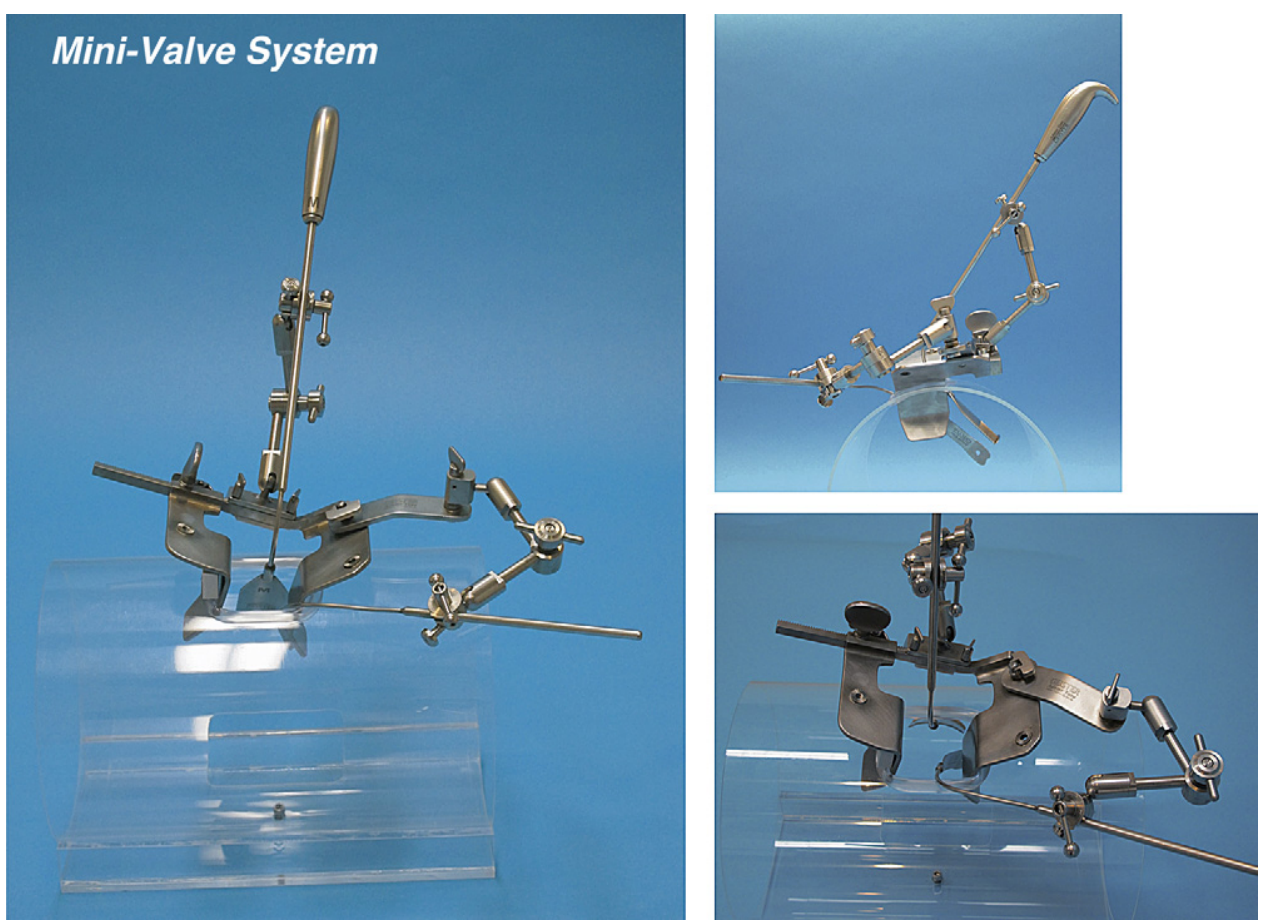

FIGURE 1. Mini-valve system is composed of a mini-thoracotomy spreader with a tilted blade, a left atrial retractor that moves flexibly, and an additional blade for the posterolateral wall of the left atrium.

advantage in dynamic distribution of forces and stress on valve components and the left ventricle. Especially in cases with broad prolapse of the posterior leaflet or with anterior leaflet prolapse, multiple chordae reconstruction using PTFE suture is essential. The loop technique is a modification that normally uses 4 premade PTFE loops to facilitate chordal reconstruction. In mini-mitral surgery with a limited working area, multiple chordal reconstructions with individual PTFE sutures are technically difficult and even dangerous because of the risk of injury in the papillary muscle. The loop technique is a feasible solution to preserve as much leaflet area as possible and to repair the broad prolapsed leaflet in mini-mitral surgery. The loop-in-loop technique avoids the surgical manipulation in the deep working area at the base of the left ventricle and facilitates multiple reconstructions of neochordae. The technique also enables reattachment of the neochordae when residual leakage is found in the saline injection test. Recently, $88.7 \%$ of mitral valve repairs were done with the loop technique, and the variation of the repair method is increasing to treat various type of mitral valve pathology.

For all these advantages in the loop technique, many surgeons still hesitate to adapt this technique because surgeons feel uncomfortable when they tie slippery PTFE (Gore-Tex) sutures many times. To solve this problem and help surgeons tie many knots with PTFE suture in the correct position, a reusable clip as a substitution for the neurosurgery clip is used to tie the PTFE suture firmly without slipping. The length of the second loop to fix the premade loops with PTFE suture is determined after filling the left ventricle with saline and appropriately positioning the clip, which can easily slide to the best position when the leakage disappears.

Although this study shows longer mean aortic crossclamp times than a previous study on mitral valve repair, the surgical outcome is excellent with no surgical mortality. This is supported by careful myocardial protection with antegrade cold-blood cardioplegia infusion under transesophageal echocardiography monitoring of the aortic valve and aortic root pressure during infusion. During cardioplegia, surgeons and anesthesiologists should ensure the aortic valve is incompetent, the cardioplegic solution is running into the coronary artery, and the aortic root pressure is sufficiently high. To afford an incompetent aortic valve, the left atrial retractor should be released during cardioplegia. The mini-valve system can aid in easy release and repositioning of the left atrial retractor after repeated cardioplegic shots. This secure strategy in myocardial protection may help beginner surgeons using the mini-mitral approach to achieve good results in cases of complex mitral valve pathology.

\section{CONCLUSIONS}

In an optimal operative setting, mitral valve repair via minithoracotomy is a feasible and durable procedure with minimal mortality and morbidity. The feasibility of multiple PTFE chordae reconstructions is an important strategy especially when trying to preserve leaflets. To reconstruct 
multiple chordae with PTFE suture, the loop technique is essential in mitral valve repair via minithoracotomy. New innovative instruments and a refined surgical setting in mini-valve surgery facilitate both direct-vision and endoscopic-assisted approaches even in complex pathology and contribute to the acceptance of mini-mitral valve surgery as a routine surgery.

\section{References}

1. Casselman FP, Van Slycke S, Wellens F, De Geest R, Degrieck I, Van Praet F, et al. Mitral valve surgery can now routinely be performed endoscopically. Circulation. 2003;108(Suppl 1):II48-54.

2. Modi P, Rodriguez E, Hargrove WC 3rd, Hassan A, Szeto WY, Chitwood WR Jr. Minimally invasive video-assisted mitral valve surgery: a 12-year, 2-center experience in 1178 patients. J Thorac Cardiovasc Surg. 2009;137:1481-7.

3. Seeburger J, Borger MA, Falk V, Kuntze T, Czesla M, Walther T, et al. Minimal invasive mitral valve repair for mitral regurgitation: results of 1339 consecutive patients. Eur J Cardiothorac Surg. 2008;34:760-5.

4. Gammie JS, Zhao Y, Peterson ED, O'Brien SM, Rankin JS, Griffith BPJ. Maxwell Chamberlain Memorial Paper for adult cardiac surgery. Less-invasive mitral valve operations: trends and outcomes from the Society of Thoracic Surgeons Adult Cardiac Surgery Database. Ann Thorac Surg. 2010;90:1401-8. 10 e1; discussion 8-10.

5. Ito T, Kudo M, Yozu R. Usefulness of osteosynthesis device made of hydroxyapatite-poly-L-lactide composites in port-access cardiac surgery. Ann Thorac Surg. 2008;86:1905-8.

6. Falk V, Seeburger J, Czesla M, Borger MA, Willige J, Kuntze T, et al. How does the use of polytetrafluoroethylene neochordae for posterior mitral valve prolapse (loop technique) compare with leaflet resection? A prospective randomized trial. J Thorac Cardiovasc Surg. 2008;136:1206.

7. Kuntze T, Borger MA, Falk V, Seeburger J, Girdauskas E, Doll N, et al. Early and mid-term results of mitral valve repair using premeasured Gore-Tex loops ('loop technique'). Eur J Cardiothorac Surg. 2008;33:566-72.

8. Kudo M, Yozu R, Kokaji K, Kimura N, Kobayashi M, Takahashi T. Examination of mitral valve repair with port-access method: aiming at early and less invasive mitral valve repair. Gen Thorac Cardiovasc Surg. 2009;57: 298-302.

9. Perier P, Stumpf J, Gotz C, Lakew F, Schneider A, Clausnizer B, et al. Valve repair for mitral regurgitation caused by isolated prolapse of the posterior leaflet. Ann Thorac Surg. 1997;64:445-50.

10. Perier P, Hohenberger W, Lakew F, Batz G, Urbanski P, Zacher M, et al. Toward a new paradigm for the reconstruction of posterior leaflet prolapse: midterm results of the "respect rather than resect" approach. Ann Thorac Surg. 2008;86:718-25. 